\title{
New parameter of roundness $R$ : circularity corrected by aspect ratio
}

\author{
Yasuhiro Takashimizu ${ }^{1 *}$ and Maiko liyoshi ${ }^{2}$
}

\begin{abstract}
In this paper, we propose a new roundness parameter $R$, to denote circularity corrected by aspect ratio. The basic concept of this new roundness parameter is given by the following equation:

$R=$ Circularity $+($ Circularity perfect circle Circularity aspect ratio)

where Circularity perfect circle is the maximum value of circularity and Circularity aspect ratio is the circularity when only the aspect ratio varies from that of a perfect circle. Based on tests of digital circle and ellipse images using Image software, the effective sizes and aspect ratios of such images for the calculation of $R$ were found to range between 100 and 1024 pixels, and 10:1 to 10:10, respectively. $R$ is thus given by

$R=C_{1}+\left(0.913-C_{A R}\right)$

where $C_{I}$ is the circularity measured using ImageJ software and $C_{A R}$ is the sixth-degree function of the aspect ratio measured using the same software. The correlation coefficient between the new parameter $R$ and Krumbein's roundness is 0.937 (adjusted coefficient of determination $=0.874$ ). Results from the application of $R$ to modern beach and slope deposits showed that $R$ is able to quantitatively separate both types of material in terms of roundness. Therefore, we believe that the new roundness parameter $R$ will be useful for performing precise statistical analyses of the roundness of particles in the future.
\end{abstract}

Keywords: Aspect ratio, Circularity, ImageJ software, Krumbein's visual roundness, Roundness

\section{Background}

Many studies have investigated particle shape in the natural world, mostly based on the definitions of sphericity and roundness of rock particles proposed by Wadell (1932). Previous studies into particle shape have been discussed in a series of review articles (e.g., Barrett 1980; Clark 1981; Winkelmolen 1982; Diepenbroek et al. 1992; Blott and Pye 2008), and in general, such studies have mainly taken one of two approaches to understanding particle shape. The first is a simple method that involves the examination of visual images of particle grains (e.g., Krumbein 1941; Rittenhouse 1943; Powers 1953; Pettijohn 1957; Lees 1963). Determining roundness using the visual roundness chart proposed by Krumbein, which is further extended in this paper, is one of the most widely employed methods. However, such a method merely compares visual images, and therefore, the derived roundness values are

\footnotetext{
* Correspondence: takashimi@ed.niigata-u.ac.jp

${ }^{1}$ Faculty of Education, Niigata University, Niigata 950-2181, Japan Full list of author information is available at the end of the article
}

not strictly quantitative. The second approach involves the quantitative determination of various shape parameters, and many evaluation methods have been designed to obtain relevant shape parameters (e.g., Schwarcz and Shane 1969; Orford and Whalley 1983; Diepenbroek et al. 1992; Yoshimura and Ogawa 1993; Vallejo and Zhou 1995; Bowman et al. 2001; Itabashi et al. 2004; Drevin 2007; Blott and Pye 2008; Lira and Pina 2009; Roussillon et al. 2009; Arasan et al. 2011; Suzuki et al. 2013, 2015). Both approaches, however, involve the analysis of each individual particle, and therefore, production of several thousand to several tens of thousands of shape parameters for reliable analysis is time consuming. Therefore, owing to the extensive time requirements and effort required for both approaches, neither is widely used, and there remains a need for an easy statistical method to derive parameters of particle shape.

In this study, we define a new roundness parameter, $R$, to denote the circularity corrected by aspect ratio, and present a case study of $R$ calculation using ImageJ software (ver. 1.47q) released from the US National

\section{Springer}


Institute of Health (Abramoff et al. 2004; Schneider et al. 2012). This represents a fairly simple method that helps to overcome the shortcomings of the previously published methods discussed above.

\section{Basic concept of this study}

The proposed concept for the new roundness parameter is quite simple: It is a correction of circularity using the aspect ratio of particles. The definition of circularity, corresponding to that of parameter $K$ defined by Cox (1927), is given as follows:

$$
\text { Circularity }=4 \pi \cdot \frac{\text { Area }}{\text { Perimeter }^{2}}
$$

This indicates that circularity can be altered in two ways: by changes in area and by changes in the perimeter of a particle. To consider this, an ideal perfect circle (true circle) is assumed. If the area and perimeter do not change, then circularity is constant. However, if only the perimeter increases and the area does not change (Fig. 1a, towards the right), then circularity decreases. An increase in the perimeter length therefore represents a decrease in the roundness of the particle. It should be noted that in this paper, we use the term "roundness" to refer to the presence or absence of surface irregularities. Therefore, with a decrease in roundness, circularity also decreases. In comparison, in the case of the ellipses skewed from a circle, if only the area decreases and the perimeter does not change, then circularity can also be seen to decrease (Fig. 1b). A decrease in area in this way represents an increase in the aspect ratio of the particle image. Therefore, with a increase in the aspect ratio, the circularity also decreases. In Fig. 1b, however, the transformed images in the center and on the right still show a high degree of roundness. Consequently, it should be possible to determine roundness if circularity can be corrected using aspect ratio. In other words, if it is possible to combine the difference in circularity value due to aspect ratio with the circularity itself, then the aspect ratio-corrected circularity can be used to represent roundness. Thus, our roundness parameter $R$ can be defined by the following equation:

$$
R=\text { Circularity }+\left(\text { Circularity }_{\text {perfect circle }}-\text { Circularity }_{\text {aspect ratio }}\right)
$$

where Circularity is the value defined by Eq. (1), Circularity ${ }_{\text {perfect }}$ circle is the maximum value of circu-

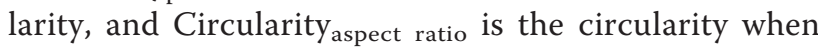
only the aspect ratio varies from that of a perfect circle.
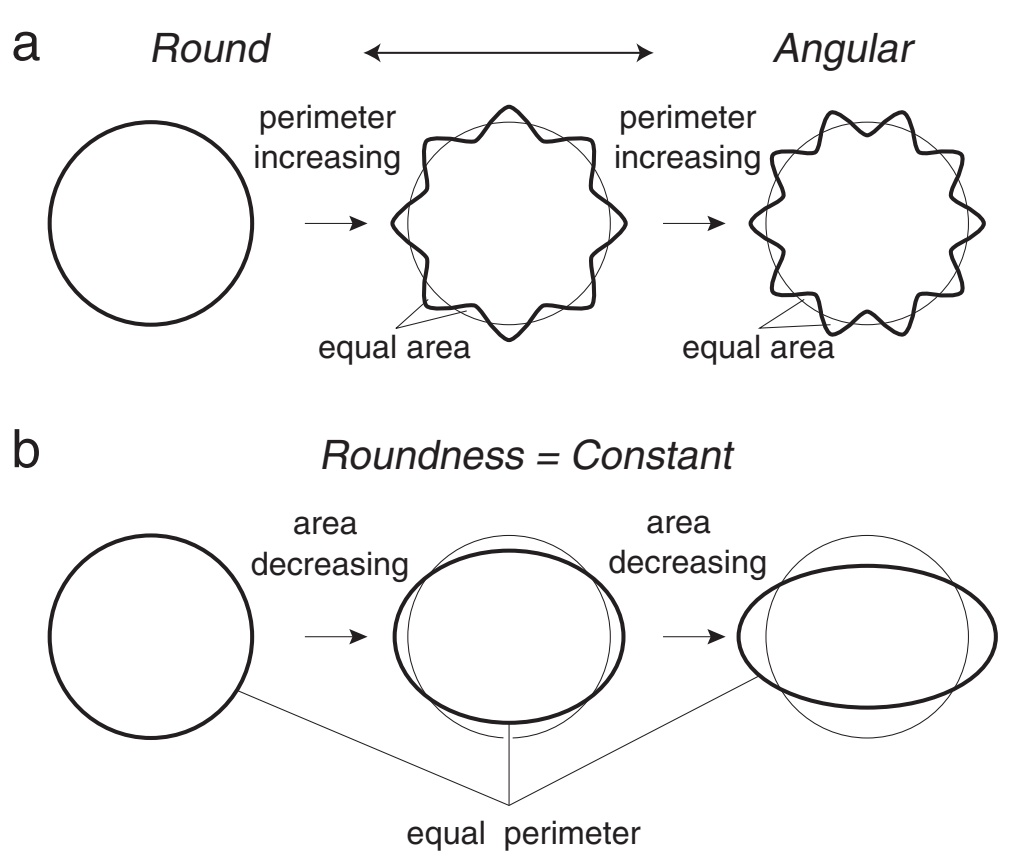

Fig. 1 Basic concept of transformation from a perfect circle. Narrow solid lines denote perfect circles before transformation. a Only the perimeter increases; the area does not change. $\mathbf{b}$ Only the area decreases; the perimeter does not change 


\section{Case study of parameter $\boldsymbol{R}$ calculation using ImageJ software}

In this chapter, we present a specific case study, demonstrating the calculation of the parameter $R$ defined in the previous chapter, using ImageJ software.

\section{Methods}

Test digital images were produced using Adobe Photoshop CS4 and Adobe Illustrator CS4. Shape parameters, including area, perimeter, circularity, aspect ratio, major axis length, and minor axis length, were measured from the test digital images using ImageJ software (ver. 1.47q). To validate the effectiveness of $R$ defined in this paper, digital images of Krumbein's original visual images (Krumbein 1941) were captured using a Fuji Xerox ApeosPort-IV C7780 scanner with a resolution of $600 \times$ 600 dots per inch and a grayscale color profile; they were saved in a TIF image file format.

Grain-size distributions of modern slope and beach sediments were measured using a sieve ranging from -5.0 to $4.0 \mathrm{phi}$, with 0.5 phi intervals. The first quartile (twenty-fifth percentile), second quartile (median), and third quartile (seventy-fifth percentile) of grain size were obtained for each from the cumulative curves.

To obtain the new roundness parameter $R$ value for these modern slope and beach sediments, we used an Olympus TG-1 digital camera to acquire digital images of particles in each grain-size class. Image analysis was then conducted separately for each grain-size fraction. The measurement of grain sizes in this analysis ranged from values equal to or coarser than 1.0 phi, with 0.5 phi intervals, with the finer limit $(1.0 \mathrm{phi})$ of the measurement range determined by the limitations of the Olympus TG-1. This range was sufficient for comparing the sediments in this study, because of the coarseness of the material. For imaging, the particles were laid out on a transparent board. As the minor $c$-axes of the particles in this layout were nearly perpendicular to the board, we assumed that an imaginary plane perpendicular to the $c$-axis, which included the major and intermediate $a$ - and $b$-axes, respectively, was parallel to the board. To obtain sharp silhouettes of particles, the light source was placed on the opposite side of the digital camera, allowing intentional capture of backlit images. The major lengths of the silhouettes were then adjusted to be more than 100 pixels. The digital images taken by Olympus TG-1 were transferred to the ImageJ software and processed into binary images. The circularity and aspect ratio of the silhouettes in the digital binary images were then measured using the ImageJ software, and the $R$ values were obtained using Eq. (8) described below. The obtained $R$ values for each grain-size class were integrated into a total $R$ distribution for the individual samples using the weight percent of each grain size class. The calculated $R$ distributions thus ranged from 0.400 to 0.925 with 0.025 intervals. The first quartile,

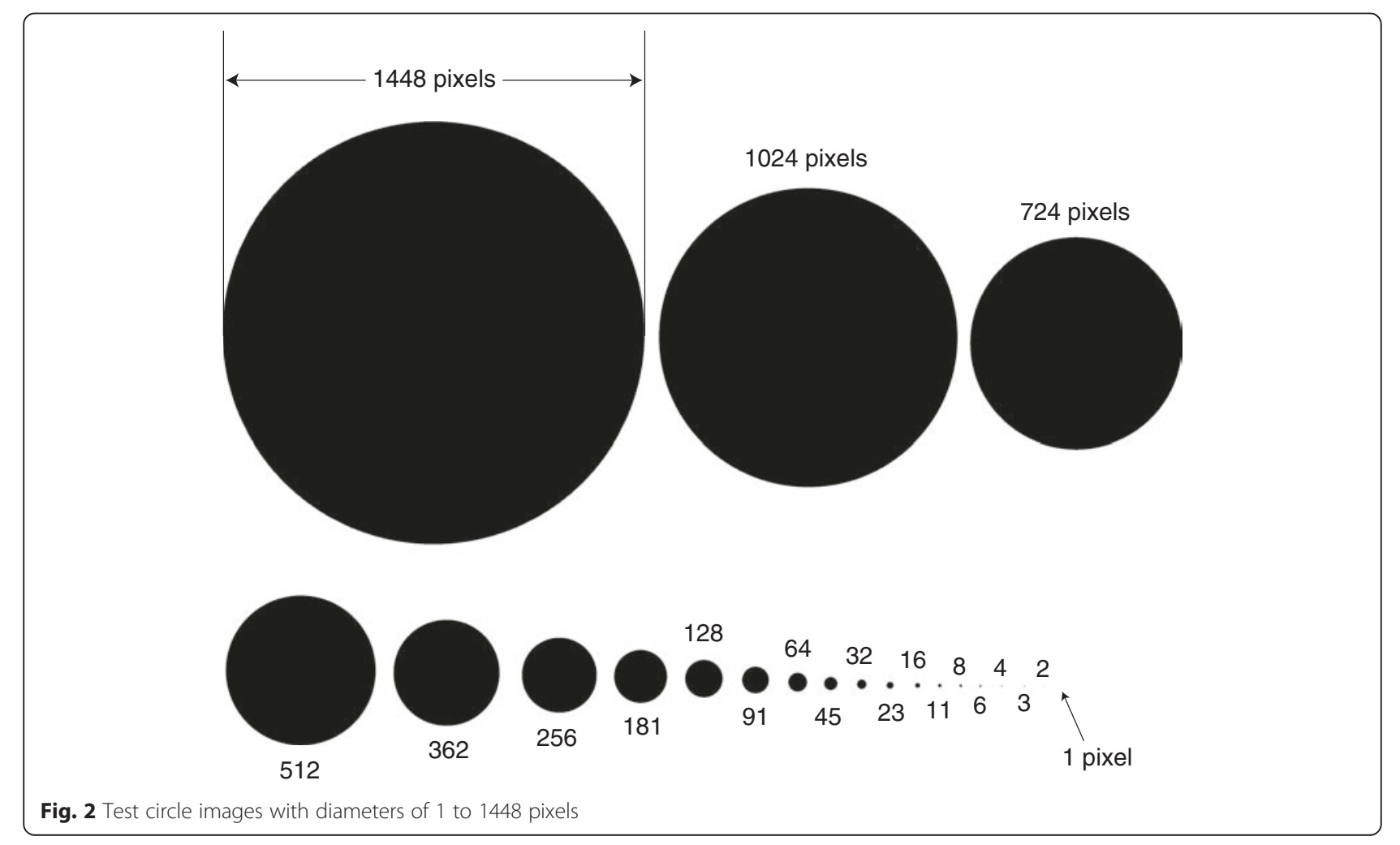


Table 1 Results of error of area and perimeter for various sizes of test circle images

\begin{tabular}{|c|c|c|c|c|c|c|c|}
\hline \multirow{2}{*}{$\begin{array}{l}\text { Width of test circle } \\
\text { image (pixel) }\end{array}$} & \multirow{2}{*}{$\begin{array}{l}A_{l} \\
\text { Area measured by } \\
\text { ImageJ (pixel) }\end{array}$} & \multirow{2}{*}{$\begin{array}{l}P_{\mathrm{I}} \\
\text { Perimeter measured } \\
\text { by ImageJ (pixel) }\end{array}$} & \multirow{2}{*}{$\begin{array}{l}2 \cdot r \\
\text { Major and minor axis length } \\
\text { measured by ImageJ }\end{array}$} & \multirow{2}{*}{$\begin{array}{l}\text { A } \\
\text { Area calculated by } p \cdot r^{2}\end{array}$} & \multirow{2}{*}{$\begin{array}{l}P \\
\text { Perimeter calculated by } 2 \cdot p \cdot r\end{array}$} & \multirow[t]{2}{*}{$\Delta A(\%)$} & \multirow[t]{2}{*}{$\Delta P(\%)$} \\
\hline & & & & & & & \\
\hline 1 & 1 & 2.828 & 1.128 & 0.999328 & 3.543716 & 0.067260 & -20.196760 \\
\hline 2 & 4 & 5.657 & 2.257 & 4.000856 & 7.090573 & -0.021393 & -20.218015 \\
\hline 3 & 9 & 9.657 & 3.385 & 8.999267 & 10.634289 & 0.008145 & -9.189979 \\
\hline 4 & 12 & 11.314 & 3.909 & 12.001102 & 12.280483 & -0.009184 & -7.870074 \\
\hline 6 & 32 & 19.314 & 6.383 & 31.999226 & 20.052782 & 0.002417 & -3.684186 \\
\hline 8 & 52 & 24.971 & 8.137 & 52.001806 & 25.563134 & -0.003472 & -2.316360 \\
\hline 11 & 97 & 34.627 & 11.113 & 96.995686 & 34.912512 & 0.004447 & -0.817792 \\
\hline 16 & 208 & 52.284 & 16.274 & 208.007222 & 51.126268 & -0.003472 & 2.264456 \\
\hline 23 & 421 & 75.598 & 23.152 & 420.985191 & 72.734138 & 0.003518 & 3.937439 \\
\hline 32 & 804 & 104.569 & 31.995 & 803.996244 & 100.515236 & 0.000467 & 4.032985 \\
\hline 45 & 1581 & 147.196 & 44.866 & 1580.973153 & 140.950667 & 0.001698 & 4.430865 \\
\hline 64 & 3196 & 211.48 & 63.791 & 3196.013548 & 200.405295 & -0.000424 & 5.526154 \\
\hline 90 & 6320 & 296.735 & 89.704 & 6319.946608 & 281.813369 & 0.000845 & 5.294863 \\
\hline 128 & 12,796 & 422.96 & 127.642 & 12796.081336 & 400.999086 & -0.000636 & 5.476550 \\
\hline 181 & 25,565 & 597.47 & 180.417 & 25564.935720 & 566.796604 & 0.000251 & 5.411711 \\
\hline 254 & 51,104 & 842.607 & 255.084 & 51104.156942 & 801.369854 & -0.000307 & 5.145832 \\
\hline 360 & 102,252 & 1193.97 & 360.82 & 102251.807881 & 1133.549225 & 0.000188 & 5.330229 \\
\hline 510 & 204,520 & 1690.871 & 510.297 & 204520.017549 & 1603.144973 & -0.000009 & 5.472121 \\
\hline 722 & 408,932 & 2391.253 & 721.574 & 408932.420696 & 2266.891106 & -0.000103 & 5.486011 \\
\hline 1020 & 818,196 & 3381.743 & 1020.666 & 818195.500707 & 3206.516140 & 0.000061 & 5.464712 \\
\hline 1442 & $1,636,024$ & 4893.536 & 1443.278 & 1636024.391899 & 4534.190619 & -0.000024 & 7.925238 \\
\hline
\end{tabular}

$p=3.141592$ 


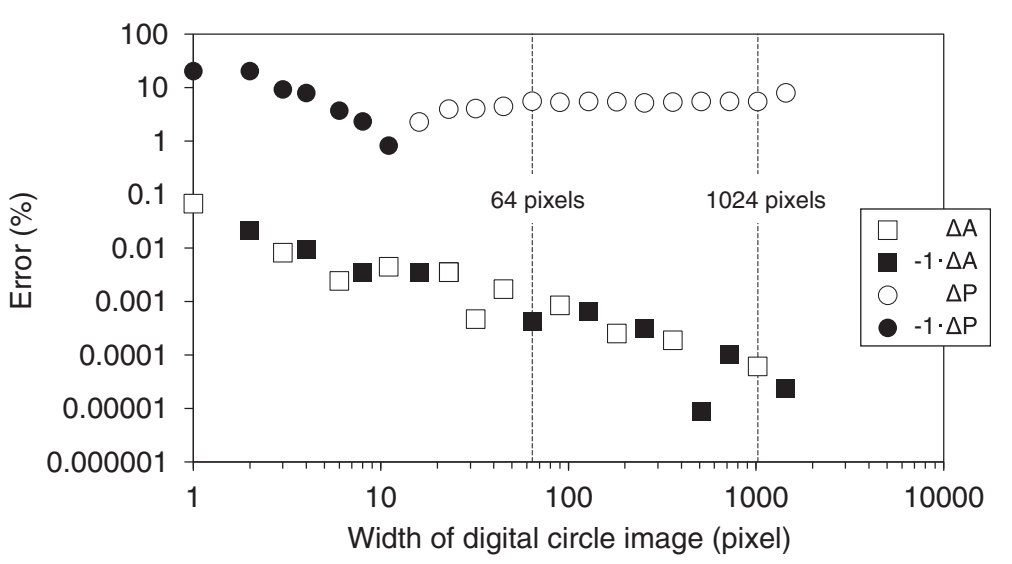

Fig. 3 Plot of the diameter of a digital circle image (pixels) and error (\%) in the area and perimeter estimations

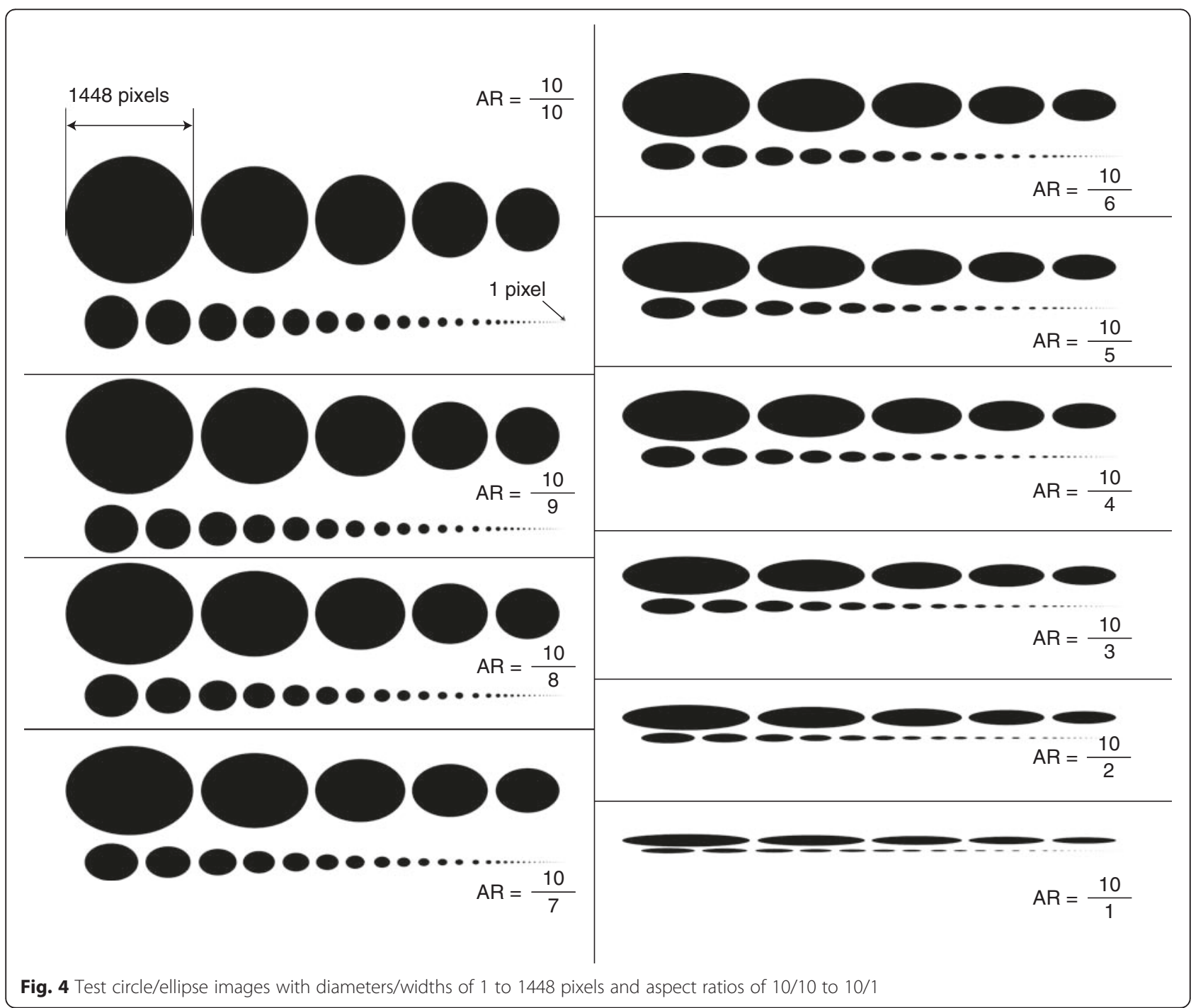




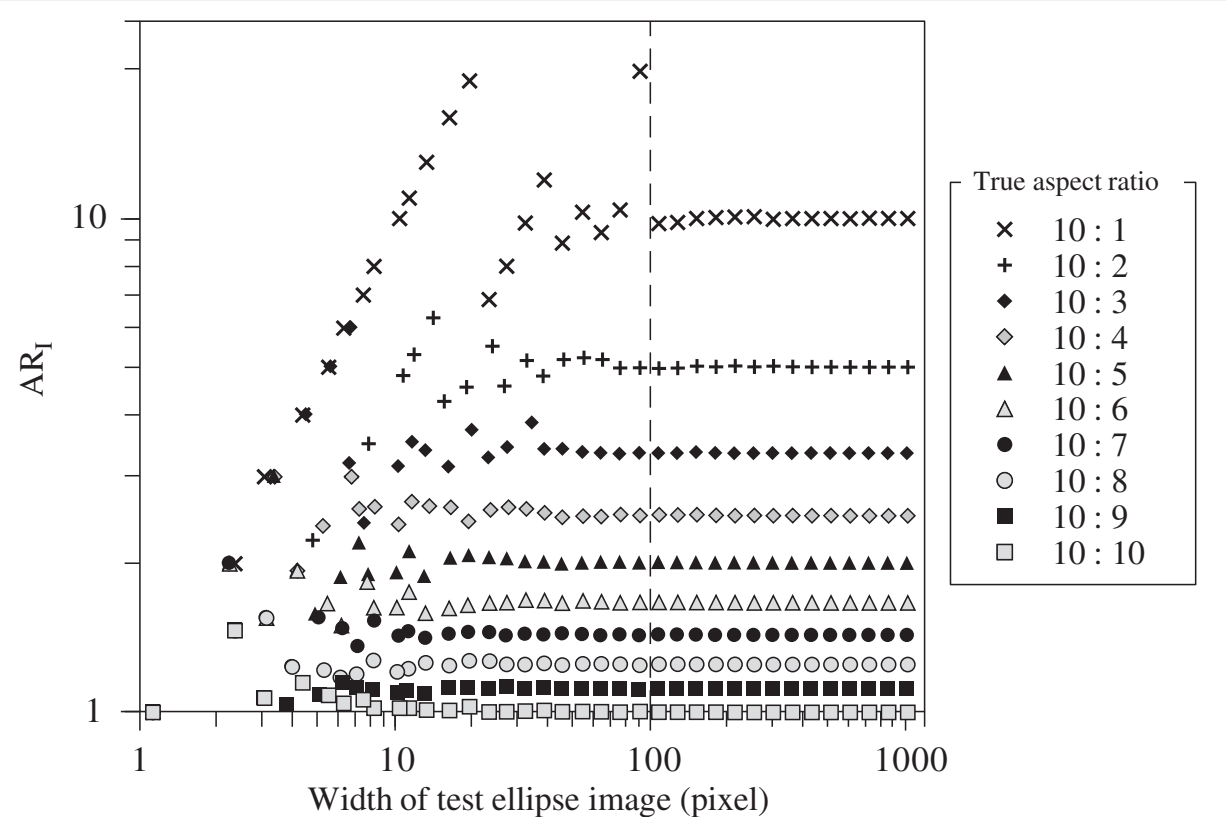

Fig. 5 Plot of the diameter of a digital circle image (pixels) and the aspect ratio calculated using ImageJ (AR,

median, and third quartile of $R$ were calculated using Microsoft Excel 2007 software.

\section{Validation of the effective resolution of digital images using ImageJ software}

A digital image is an aggregate of pixels, which are the minimum units of the image. Hence, there should be an error in shape parameter values between the geometrically obtained true values and those calculated from the digital image. Therefore, to obtain the most effective size of digital images for shape analysis, we examined the errors in basic shape parameters, including area, perimeter, and aspect ratio, using ImageJ software.

\section{Area and perimeter}

First, the area $\left(A_{\mathrm{I}}\right)$, perimeter $\left(P_{\mathrm{I}}\right)$, and major and minor axis lengths of the fit ellipses $(2 \cdot r$; both lengths are equal) of twelve test circle images with diameter lengths of 1 to 21 pixels, produced using Adobe Photoshop CS4, were calculated using ImageJ software (Fig. 2). To calculate the area and perimeter, the measuring algorithms of the ImageJ software were sought from the manual. However, there were no detailed descriptions of the algorithms, so we investigated the value determinations ourselves. The obtained algorithms are therefore as follows. $A_{\mathrm{I}}$ is equal to the total number of pixels in a grain. For test circle images with a diameter length of 1 to 2 pixels, $P_{\mathrm{I}}$ was calculated by determining the geometric mean of the numbers of pixels in the images and the numbers of circumscribed pixels in the images. In contrast, for test circle images with diameter lengths greater than 2 pixels, $P_{\mathrm{I}}$ was the sum of the marginal pixels, in which the sizes of pixels located at the corners are assumed to be $2^{0.5}$, while those of other pixels is 1 . The major axis length of the test circle images was $2 \cdot r$, because all of the test images comprised perfect circles. The error $(\Delta A)$ between the area measured using ImageJ software $\left(A_{\mathrm{I}}\right)$ and the area calculated from radius length $(A)$, and the error $(\Delta P)$ between $P_{\mathrm{I}}$ and the perimeter obtained by the geometric procedure $(P)$, were therefore determined as follows (Table 1):

$$
\begin{aligned}
& \Delta A=\left(\frac{A_{\mathrm{I}}-A}{A}\right) \cdot 100 \\
& \Delta P=\left(\frac{P_{\mathrm{I}}-P}{P}\right) \cdot 100
\end{aligned}
$$

From our calculations, the absolute error for the area $(|\triangle A|)$ was found to decrease with an increase in the diameter of the test circle images (Table 1 and Fig. 3). All $21|\Delta A|$ values obtained in this test were below $0.1 \%$, which is sufficiently small to assume accuracy. These values are therefore sufficiently reliable for use in shape analysis. In contrast, the absolute perimeter error $|\Delta P|$ was approximately $20 \%$ for diameters of 1 to 2 pixels, but decreased with an increase in the diameter of the test circle images. $|\Delta P|$ attained a minimum of approximately $0.8 \%$ at a diameter of 11 pixels; however, the error increased again to approximately $8 \%$ for diameters of 16 to 1442 pixels. For diameters of 64 to 1024 pixels, the $|\Delta P|$ value remained constant at around $5 \%$ (Table 1 and Fig. 3). 


\section{Aspect ratio}

In this section, we examine the relationship between the aspect ratio measured using Image $\mathrm{J}$ software $\left(\mathrm{AR}_{\mathrm{I}}\right)$ and the widths of test ellipse images (Fig. 4), which were obtained by subjecting the test circle images in Fig. 2 to $10 \%$ aspect ratio deformation intervals in Adobe Photoshop CS4. The ImageJ software defines the aspect ratio as follows:

$$
\mathrm{AR}_{\mathrm{I}}=\frac{\text { major axis length of approximate ellipse }}{\text { minor axis length of approximate ellipse }}
$$

Therefore, the aspect ratio is equal to one for a perfect circle and increases with an increase in deformation. To validate this relationship for different image sizes, we prepared test circle images with diameters of $2^{0-10.5}$ (1 to 1448) pixels, and test ellipse images were obtained from

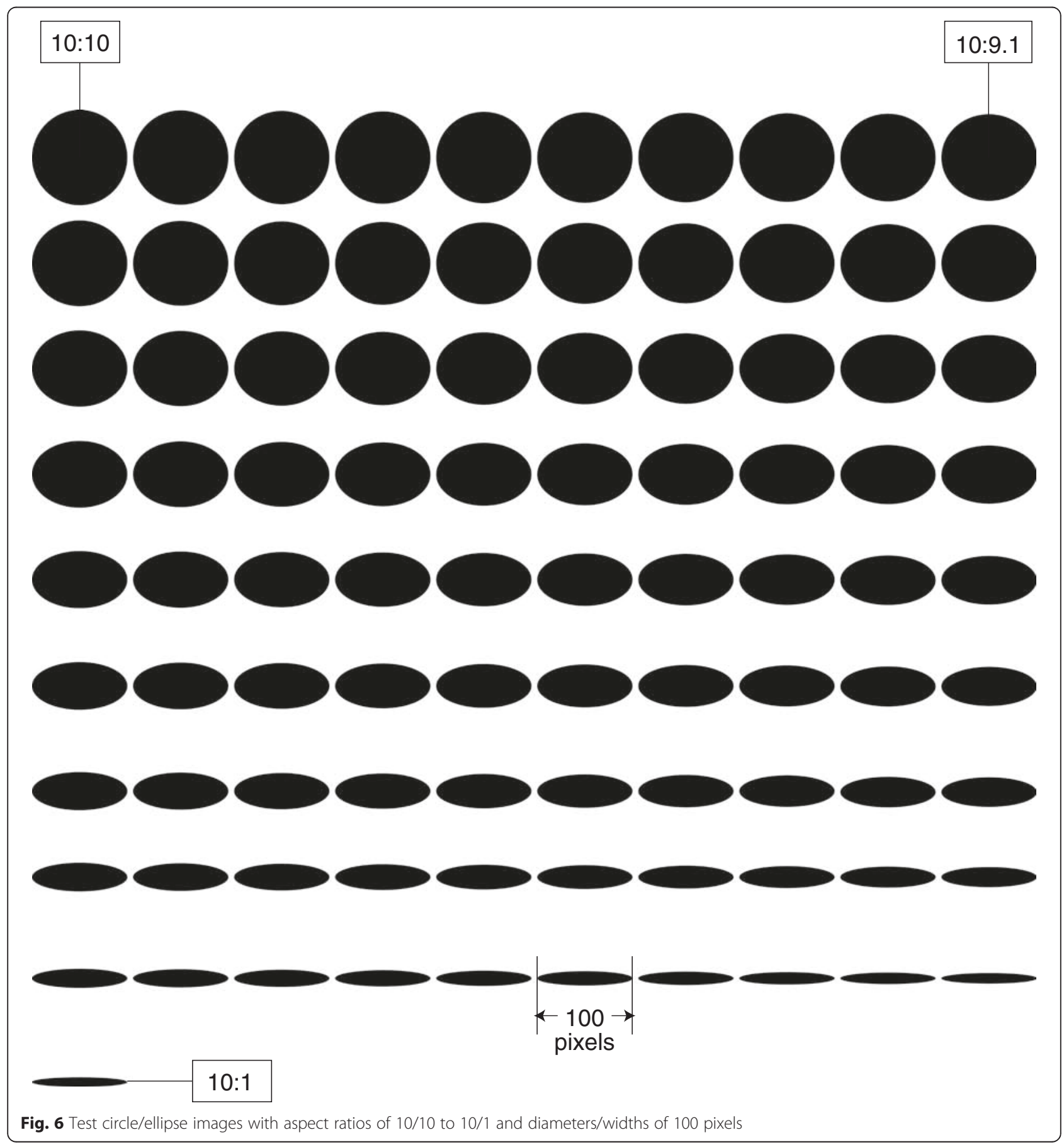


Table $2 \mathrm{Cl}$ and ARI values calculated using ImageJ applied to the test images of Fig. 6

\begin{tabular}{|c|c|c|c|c|c|c|c|c|}
\hline aspect ratio of test ellipse image & $\mathrm{Cl}$ & ARI & aspect ratio of test ellipse image & $\mathrm{Cl}$ & ARI & aspect ratio of test ellipse image & $\mathrm{Cl}$ & ARI \\
\hline $10: 10.0$ & 0.911 & 1.000 & $10: 6.9$ & 0.871 & 1.449 & $10: 3.8$ & 0.668 & 2.626 \\
\hline 10:9.9 & 0.905 & 1.010 & $10: 6.8$ & 0.867 & 1.471 & $10: 3.7$ & 0.654 & 2.711 \\
\hline 10:9.8 & 0.912 & 1.020 & $10: 6.7$ & 0.860 & 1.493 & 10:3.6 & 0.646 & 2.775 \\
\hline 10:9.7 & 0.913 & 1.031 & 10:6.6 & 0.856 & 1.515 & $10: 3.5$ & 0.634 & 2.860 \\
\hline 10:9.6 & 0.912 & 1.042 & $10: 6.5$ & 0.855 & 1.539 & $10: 3.4$ & 0.621 & 2.936 \\
\hline 10:9.5 & 0.913 & 1.054 & $10: 6.4$ & 0.851 & 1.560 & 10:3.3 & 0.609 & 3.038 \\
\hline 10:9.4 & 0.909 & 1.064 & 10:6.3 & 0.845 & 1.588 & $10: 3.2$ & 0.599 & 3.116 \\
\hline 10:9.3 & 0.910 & 1.075 & $10: 6.2$ & 0.842 & 1.612 & 10:3.1 & 0.583 & 3.230 \\
\hline 10:9.2 & 0.909 & 1.087 & $10: 6.1$ & 0.836 & 1.641 & 10:3.0 & 0.570 & 3.335 \\
\hline 10:9.1 & 0.910 & 1.099 & $10: 6.0$ & 0.832 & 1.665 & $10: 2.9$ & 0.558 & 3.439 \\
\hline 10:9.0 & 0.904 & 1.110 & 10:5.9 & 0.826 & 1.694 & $10: 2.8$ & 0.545 & 3.573 \\
\hline 10:8.9 & 0.906 & 1.123 & 10:5.8 & 0.822 & 1.724 & $10: 2.7$ & 0.530 & 3.696 \\
\hline 10:8.8 & 0.904 & 1.136 & 10:5.7 & 0.815 & 1.756 & $10: 2.6$ & 0.516 & 3.847 \\
\hline 10:8.7 & 0.909 & 1.149 & 10:5.6 & 0.810 & 1.785 & $10: 2.5$ & 0.503 & 3.984 \\
\hline 10:8.6 & 0.902 & 1.161 & $10: 5.5$ & 0.807 & 1.816 & $10: 2.4$ & 0.486 & 4.172 \\
\hline 10:8.5 & 0.905 & 1.175 & $10: 5.4$ & 0.798 & 1.851 & $10: 2.3$ & 0.470 & 4.338 \\
\hline 10:8.4 & 0.898 & 1.190 & 10:5.3 & 0.791 & 1.887 & $10: 2.2$ & 0.453 & 4.549 \\
\hline 10:8.3 & 0.901 & 1.205 & $10: 5.2$ & 0.777 & 1.924 & 10:2.1 & 0.438 & 4.755 \\
\hline 10:8.2 & 0.897 & 1.219 & 10:5.1 & 0.780 & 1.959 & $10: 2.0$ & 0.422 & 5.009 \\
\hline 10:8.1 & 0.898 & 1.234 & 10:5.0 & 0.773 & 2.002 & 10:1.9 & 0.405 & 5.236 \\
\hline 10:8.0 & 0.891 & 1.250 & $10: 4.9$ & 0.761 & 2.039 & $10: 1.8$ & 0.386 & 5.570 \\
\hline 10:7.9 & 0.893 & 1.265 & $10: 4.8$ & 0.758 & 2.082 & 10:1.7 & 0.369 & 5.860 \\
\hline 10:7.8 & 0.886 & 1.281 & $10: 4.7$ & 0.748 & 2.127 & 10:1.6 & 0.350 & 6.260 \\
\hline 10:7.7 & 0.892 & 1.298 & $10: 4.6$ & 0.741 & 2.173 & $11: 1.5$ & 0.334 & 6.636 \\
\hline 10:7.6 & 0.886 & 1.315 & $10: 4.5$ & 0.733 & 2.221 & $12: 1.4$ & 0.31 & 7.15 \\
\hline 10:7.5 & 0.89 & 1.33 & $10: 4.4$ & 0.72 & 2.27 & $13: 1.3$ & 0.29 & 7.64 \\
\hline 10:7.4 & 0.88 & 1.35 & $10: 4.3$ & 0.72 & 2.32 & $14: 1.2$ & 0.27 & 8.34 \\
\hline 10:7.3 & 0.88 & 1.37 & $10: 4.2$ & 0.7 & 2.38 & $15: 1.1$ & 0.25 & 8.98 \\
\hline 10:7.2 & 0.88 & 1.39 & 10:4.1 & 0.7 & 2.44 & $16: 1.0$ & 0.23 & 10.05 \\
\hline 10:7.1 & 0.88 & 1.41 & $10: 4.0$ & 0.68 & 2.5 & & & \\
\hline 10:7.0 & 0.87 & 1.43 & 10:3.9 & 0.68 & 2.57 & & & \\
\hline
\end{tabular}




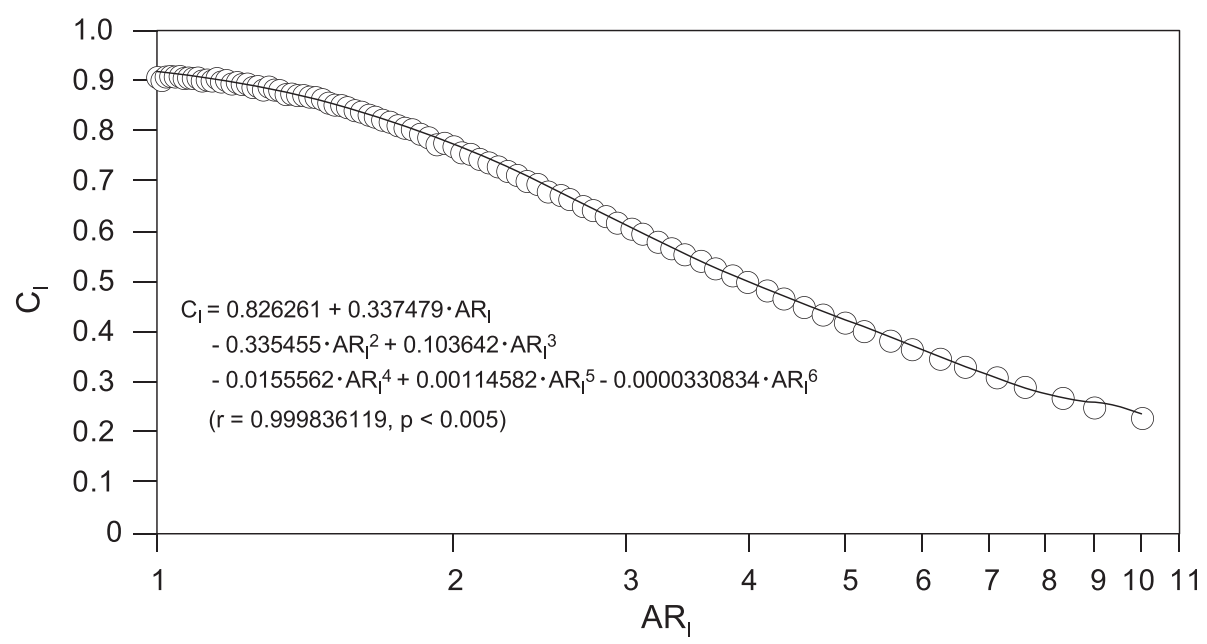

Fig. 7 Plot of $A R_{I}$ and $C_{I}$ values of the test images, calculated using ImageJ software. Solid line represents a sixth-degree polynomial

the test circle images through $10 \%$ deformation intervals in height (Fig. 4). As such, $\mathrm{AR}_{I}$ showed a range of values, controlled by the widths of the test circle/ellipse images (Fig. 5). Notably, the test circle/ellipse images with diameters or widths of less than 100 pixels are unstable, as shown in Fig. 5. However, the widths of the test circle/ ellipse images greater than or equal to 100 pixels can be seen to remain constant.

\section{Effective size range of digital images in this study}

The above results can be summarized as follows: (1) The $|\Delta A|$ values are sufficiently small to assume accuracy for all test circle images with diameters ranging from 1 to 1442 pixels; (2) The $|\Delta P|$ value is constant, at approximately $5 \%$, for test circle images with diameters of 64 to 1024 pixels; and (3) The $\mathrm{AR}_{\mathrm{I}}$ value for the test circle/ ellipse images with widths greater than or equal to 100 pixels, and a true aspect ratio greater than or equal to 10:1, remains constant. Consequently, in this paper, we consider the effective size and aspect ratios of digital images for shape analysis using ImageJ software, to be 100 to 1024 pixels and 10:1 to 10:10, respectively.

\section{Relationship between aspect ratio and circularity in ImageJ software \\ Circularity in ImageJ software}

Circularity can be calculated as a shape parameter index in the ImageJ software. The definition of circularity $\left(C_{\mathrm{I}}\right)$ in the Image J software is as follows:

$$
C_{\mathrm{I}}=4 \pi \cdot \frac{A_{\mathrm{I}}}{P_{\mathrm{I}}^{2}}
$$

where $A_{\mathrm{I}}$ and $P_{\mathrm{I}}$ are the area and perimeter measured using ImageJ (ImageJ User 2012), respectively. This therefore implies that $C_{\mathrm{I}}$ is directly determined by $A_{\mathrm{I}}$ and $P_{\mathrm{I}}$. For instance, if their two different $P_{\mathrm{I}}$ values are provided

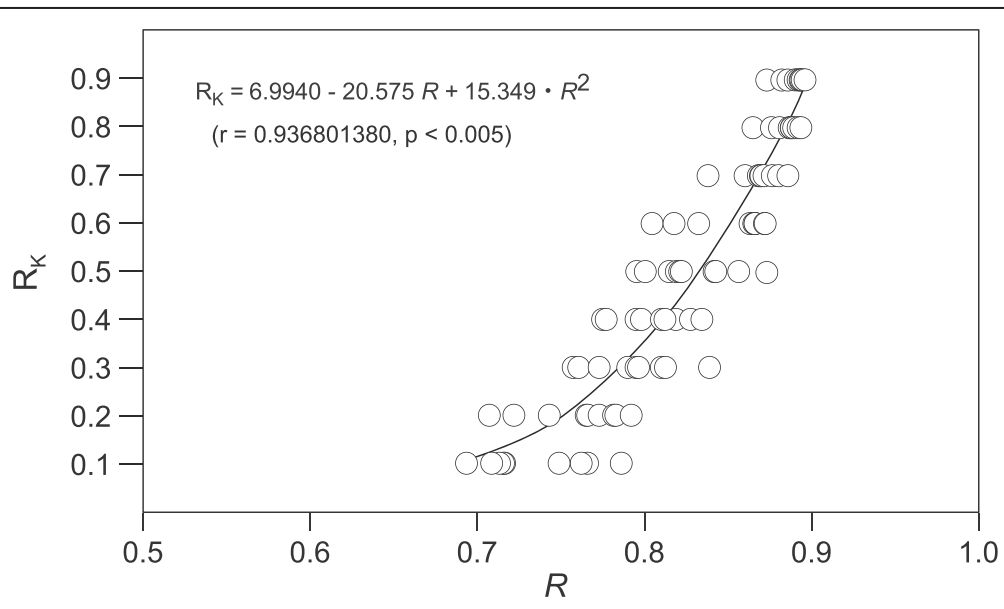

Fig. 8 Plot of $R_{K}$ and $R$ values derived in this study. Solid line represents the quadratic regression 
for digital images with the same $A_{\mathrm{I}}$ values, the image showing high circularity will have a shorter perimeter than that of the other image.

\section{Relationship between circularity and aspect ratio in ImageJ software}

When considering roundness as a shape parameter, the degree of roundness of a deformed circle (ellipse) image should be the same as that of a perfect circle image. Different values of $C_{\mathrm{I}}$ will therefore correspond to changes in aspect ratio, and $C_{\mathrm{I}}$ alone should not be used as a roundness shape parameter. For this reason, the relationship between $C_{\mathrm{I}}$ and $\mathrm{AR}_{\mathrm{I}}$ is examined in this section, and we attempt to correct $C_{\mathrm{I}}$ using $\mathrm{AR}_{\mathrm{I}}$.

First, a test circle image with a diameter of 100 pixels was produced using Adobe Illustrator CS4. Then, 91 test ellipse images were obtained by deforming a test circle image, in $0.1 \%$ height intervals (Fig. 6). From the shape analysis of circularity and aspect ratio using ImageJ software, the triadic relationship between the true aspect ratio, $C_{\mathrm{I}}$, and $\mathrm{AR}_{\mathrm{I}}$ could be obtained (Table 2). $\mathrm{AR}_{\mathrm{I}}$ versus $C_{\mathrm{I}}$ is plotted in Fig. 7. It should be noted that the maximum $C_{\mathrm{I}}$ value is 0.913 (Table 2), as ImageJ is unable to output 1.0 as a maximum value for these test images, because the digital images comprise an aggregate of pixels and include errors. We used a polynomial regression to analyze the relationships. From this analysis, a sixth-degree polynomial was obtained for the relationship, with a strong correlation $(r=0.999836119$, $p<0.005$, adjusted coefficient of determination $=$
0.999648855; solid curve in Fig. 7). Thus, the estimated regression equation for the survey line is

$$
\begin{aligned}
C_{\mathrm{I}}= & 0.826261+0.337479 \cdot \mathrm{AR}_{\mathrm{I}}-0.335455 \cdot \mathrm{AR}_{\mathrm{I}}^{2} \\
& +0.103642 \cdot \mathrm{AR}_{\mathrm{I}}^{3}-0.0155562 \cdot \mathrm{AR}_{\mathrm{I}}^{4} \\
& +0.00114582 \cdot \mathrm{AR}_{\mathrm{I}}^{5}-0.0000330834 \cdot \mathrm{AR}_{\mathrm{I}}^{6}
\end{aligned}
$$

where $C_{\mathrm{I}}$ is the circularity calculated using ImageJ software and $A R_{I}$ is the aspect ratio calculated using the same software. This indicates that $C_{\mathrm{I}}$ is a sixth-degree polynomial of $A R_{I}$ when test ellipse images are made from the deformation of a perfect circle image with $0.1 \%$ intervals in height. We therefore refer to the $C_{\mathrm{I}}$ value newly derived from this regression equation as $C_{\mathrm{AR}}$.

\section{Calculating roundness parameter $R$ using ImageJ software}

Equation (7) implies that the circularity of a perfect circle changes with varying aspect ratio. This means that if a shape's perimeter is highly rounded, then the degree of roundness should also be close to 0.913 . Therefore, after the correction of circularity by aspect ratio, which represents the addition of the difference between 0.913 and $C_{\mathrm{AR}}$ to $C_{\mathrm{I}}$, it is possible to calculate the circularity without considering aspect ratio. The corrected circularity is therefore considered the new roundness parameter $(R)$ and can be presented as follows:

$$
R=C_{\mathrm{I}}+\left(0.913-C_{\mathrm{AR}}\right)
$$

When using $R$ in particle shape analysis, the roundness values can be easily handled as numerical data.

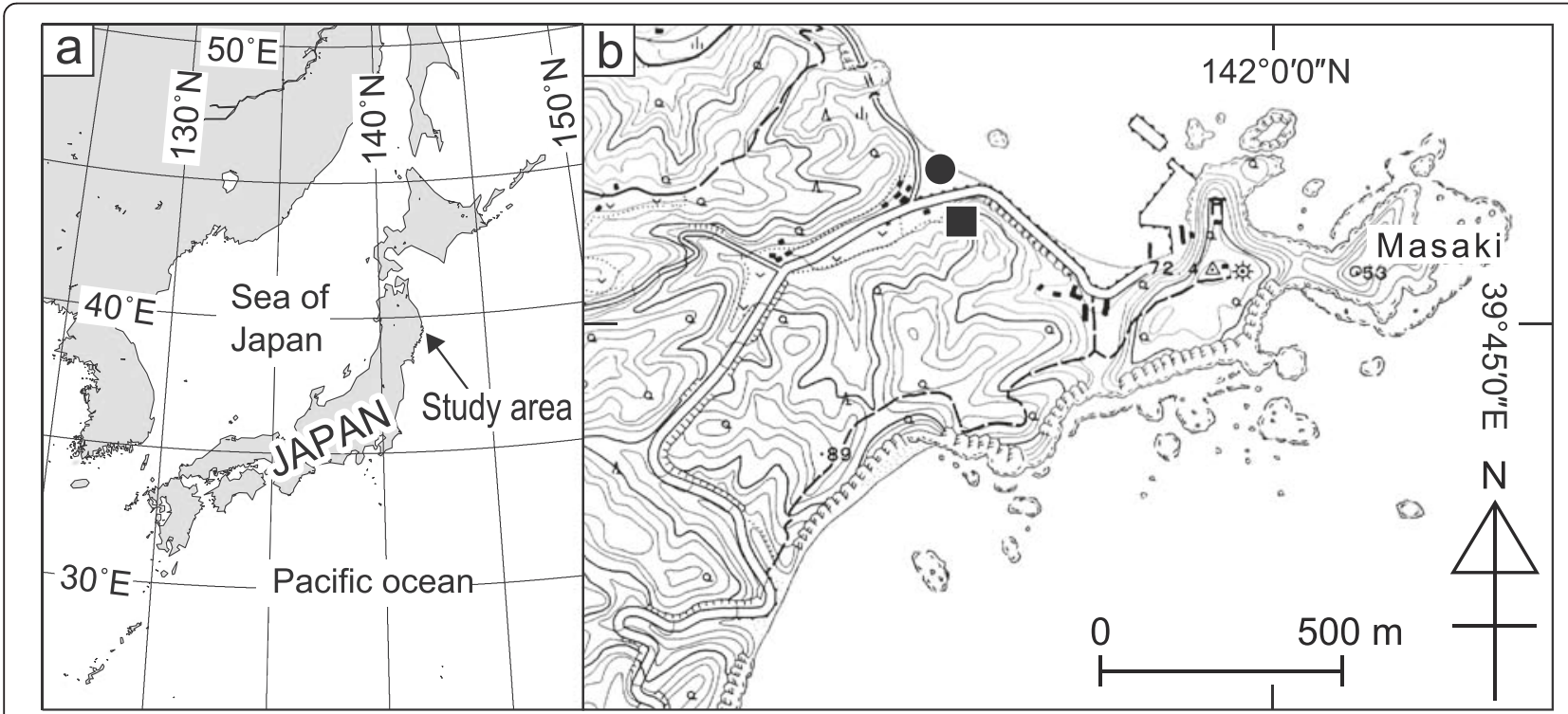

Fig. 9 Location of the study area. a Large-scale map of study area in Northeastern Japan and facing the Pacific Ocean. b Detailed map with sampling location in the Masaki area of Iwate Prefecture, Northeastern Japan. Location map is based on "Taro," the 1:25,000 topographic map from the Geographical Survey Institute (GSI) of Japan. Solid circle and solid square indicate beach and slope deposits, respectively 
For instance, the first quartile (twenty-fifth percentile), second percentile (median), and third quartile (seventy-fifth percentile) of the roundness of a large number of particle grains can be easily and quickly examined.
Validation of $R$ using Krumbein's pebble images for visual roundness

In order to validate the effectiveness of $R$ defined in this paper, the $R$ values of Krumbein's visual images were calculated and examined. Figure 8 plots Krumbein's roundness

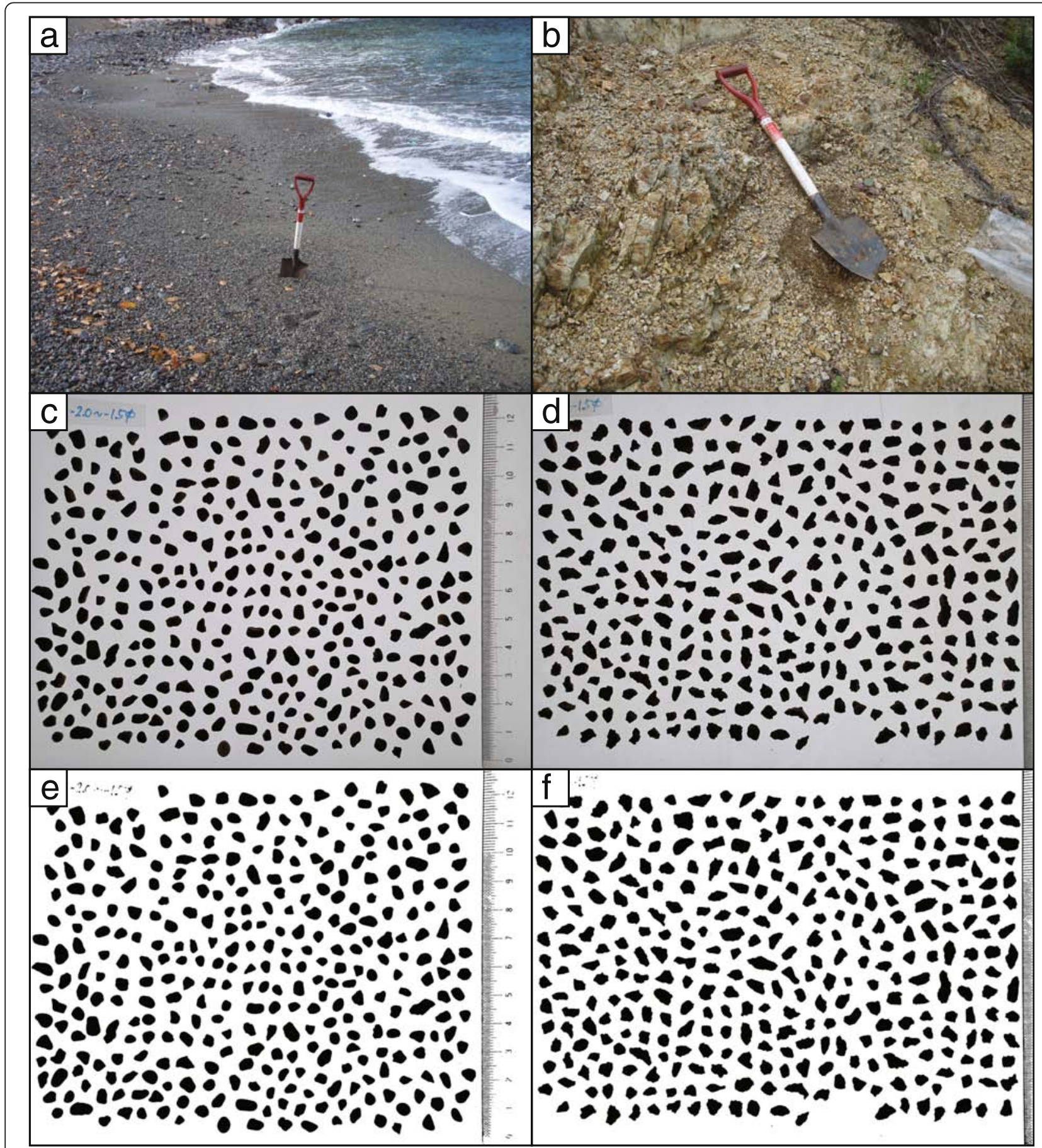

Fig. 10 Photographs and binary images of sediment particles. These were obtained from beach and slope environments and grain size ranges from -1.5 to 2.0 phi. Photographs of $\mathbf{a}$ beach sediments and $\mathbf{b}$ slope sediments (scoop length is $82 \mathrm{~cm}$ ); photographs of prepared samples of $\mathbf{c}$ beach sediments and $\mathbf{d}$ slope deposits; binary images processed by Image $\mathrm{J}$ of $\mathbf{e}$ beach sediments and $\mathbf{f}$ slope deposits 


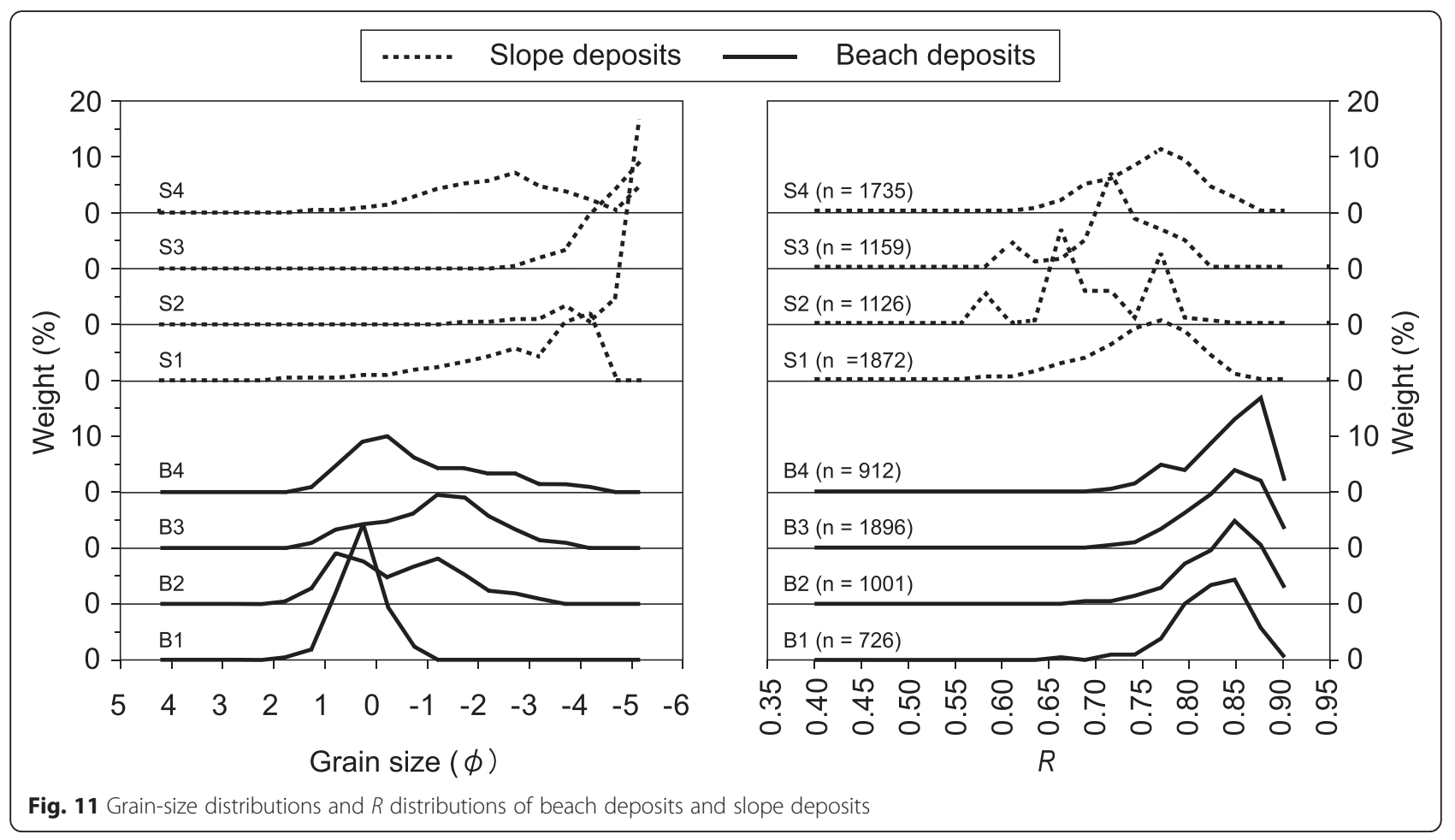

$\left(R_{K}\right)$ against the $R$ values calculated using the method defined in this study. From this analysis, a second-degree polynomial was obtained for the relationship, with strong correlation $(r=0.936801380, p<0.005$; adjusted coefficient of determination $=0.874458283$; Fig. 8 ), and the estimated regression equation for the survey line is therefore

$$
R_{K}=6.9940-20.575 \cdot R+15.349 \cdot R^{2}
$$

This implies that $R$ is an effective parameter for roundness.
Correlation analyses have been conducted, comparing shape parameters and the roundness of Krumbein's visual images, by many previous authors (Table 3 ). These previously published shape parameters were calculated through various methods, including Fourier analysis (Mi: Itabashi et al. 2004), fractal analysis ( $D$ : Vallejo and Zhou 1995; FD: Itabashi et al. 2004), and computer-assisted geometrical analysis (FU: Itabashi et al. 2004; rW: Roussillon et al. 2009). Strong correlation coefficients were obtained between these shape parameters and the Krumbein's (1941)

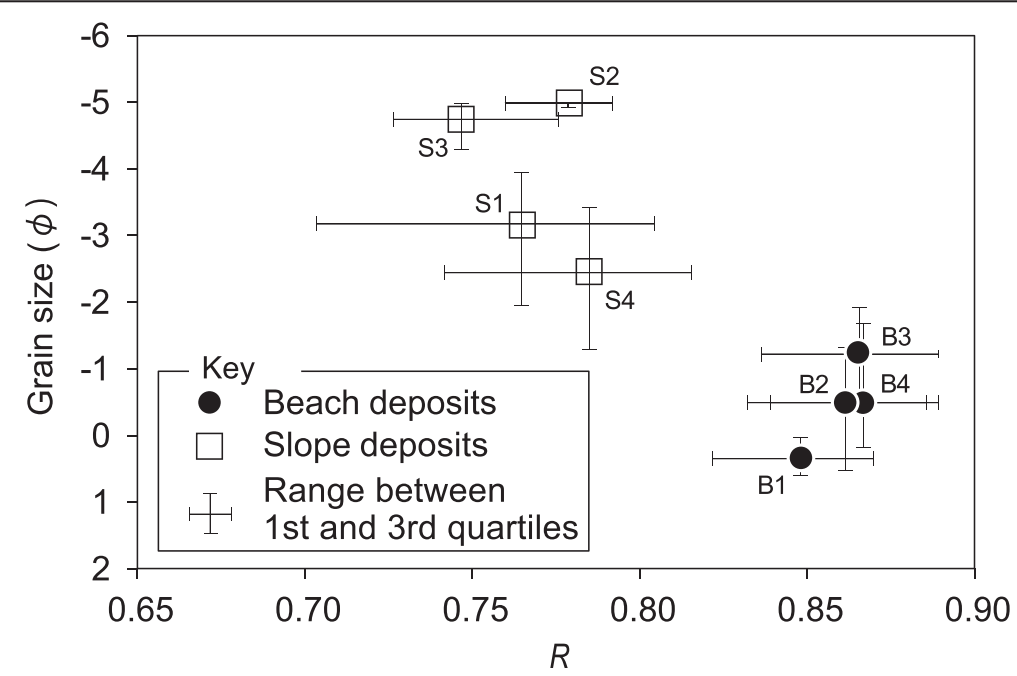

Fig. 12 Plot of median $R$ versus median grain size for modern sedimentary materials. Solid circles and solid squares indicate beach and slope deposits, respectively. Vertical and horizontal error bars represent the ranges between the first and third quartiles 
Table 3 Correlation and regression expression between shape parameters values and the Krumbein's visual images

\begin{tabular}{|c|c|c|c|c|c|c|}
\hline \multirow{2}{*}{$\begin{array}{l}\text { Shape } \\
\text { parameters }\end{array}$} & \multicolumn{4}{|c|}{ Correlation coefficient } & \multirow[t]{2}{*}{ Regression expressions } & \multirow[t]{2}{*}{ References } \\
\hline & $\begin{array}{l}\text { Individual values }{ }^{a} \\
(n=81)\end{array}$ & $\begin{array}{l}\text { Adjusted coefficient of determination } \\
\text { of individual values }(n=81)\end{array}$ & Mean values $(n=9)$ & $\begin{array}{l}\text { Adjusted coefficient of determination } \\
\text { of mean values }(n=9)\end{array}$ & & \\
\hline \multirow[t]{2}{*}{$\bar{D}$} & \multirow[t]{2}{*}{-} & \multirow[t]{2}{*}{-} & \multirow[t]{2}{*}{$0.778^{b}$} & \multirow[t]{2}{*}{$0.549^{b}$} & $D=1.0541-0.0335 \cdot R_{k}$ & \multirow[t]{2}{*}{ Vallejo and Zhou (1995) } \\
\hline & & & & & $R_{K}=19.255-18.079 \cdot D^{c}$ & \\
\hline Mi & 0.940 & - & - & - & $M i=28.38-46.18 R_{K}+21.71 R_{K}^{2}$ & Itabashi et al. (2004) \\
\hline$F D$ & 0.939 & - & - & - & $F D=1.03655-0.05799 \cdot R_{K}+0.02698 \cdot R_{K}^{2}$ & Itabashi et al. (2004) \\
\hline$F U^{d}$ & 0.857 & - & - & - & $F U=0.0736+0.264 \cdot R_{k}$ & Itabashi et al. (2004) \\
\hline$r W$ & 0.919 & - & 0.992 & & - & Roussillon et al. (2009) \\
\hline$R$ & 0.937 & 0.874 & 0.995 & 0.987 & $R_{K}=6.9940-20.575 \cdot R+15.349 \cdot R^{2}$ & This study \\
\hline
\end{tabular}

aThe shape factor for each group is the average of nine shape factors corresponding to the nine particles forming each group in Krumbein's pebble images

${ }^{\mathrm{b}}$ This parameter is recalculated values to the third decimal place by the author

'This expression is recalculated by the author

${ }^{\mathrm{d}}$ This parameter is the same definition as circularity on ImageJ 
roundness. In particular, $M i, F D$, and $r W$ all had high correlation coefficients of more than 0.9 (0.940, 0.939, and 0.919 , respectively). Similar to these studies, the shape parameter $R$ defined in this study also exhibits a high correlation coefficient (0.937). This demonstrates that $R$ is a suitable parameter for discussing the roundness of particle grains as $M i, F D$, and $r W$.

However, $R$ has an advantage over previously defined parameters in that it can be used to easily obtain roundness values using widely available software (such as ImageJ software). Consequently, the new roundness parameter $R$ can be expected to have a significant effect on future statistical analyses of roundness. The roundness parameter $R$ is also advantageous as it can be applied as a part of simple new field studies into clastic grain shapes, which is not the case for other methods such as fractal dimensions or Fourier descriptors. This simple approach to calculating the circularity corrected by aspect ratio has a great potential that can advance research in a wide variety of scientific fields.

\section{Applying $R$ to modern deposits using ImageJ software} In this section, we apply our shape parameter to digital images of samples of sedimentary materials collected from modern beaches and slopes in the Masaki area of Eastern Japan (Figs. 9 and 10). The lithology of this region is mainly Cretaceous rhyolite, dacite, sandy siltstone, sandstone, and conglomerate (Shimazu et al. 1970). The beach deposits consist primarily of coarse-grained sands to granules with pebbles, which are well-abraded by wave action on the beach (Fig. 10a). The slope deposits in this area comprise heavily weathered Cretaceous basement rocks, which occur as angular granule- to pebble-sized clasts (Fig. 10b). Thus, the slope deposits can be considered immature clastics, while the beach deposits represent more mature clastic material. We selected these two types of materials for roundness analysis because they differ markedly in particle roundness, but both have a fairly coarse grain-size distribution.

\section{Grain size distribution}

A total of eight sedimentary samples were selected from beach and slope environments for this study, consisting of four beach deposits, referred to as B1, B2, B3, and B4, and four slope deposits, referred to as S1, S2, S3, and S4. Before shape analysis, their grain-size distributions were measured using a sieve ranging from -5.0 to 4.0 phi with 0.5 phi intervals (Fig. 11). Median grain sizes of the deposits in each environment were 0.33 (B1), -0.50 (B2), -1.25 (B3), and -0.50 (B4) phi for the beach deposits, and -3.18 (S1), -5.00 (S2), -4.77 (S3), and -2.47 (S4) phi for the slope deposits. The range between the first and third quartiles in the grain size distribution can be considered a proxy for the degree of sorting. Thus, these ranges in each environment were 0.821 to 0.869 (B1), -1.34 to 0.50 (B2), -1.93 to -0.40 (B3), and -1.70 to 0.16 (B4) phi for the beach deposits and -3.96 to -1.96 (S1), -5.00 to -4.94 (S2), -5.00 to -4.30 (S3), and -3.46 to -1.33 (S4) phi for the slope deposits. Together, these data indicate that the beach deposits were finer than the slope deposits but had similar degree of sorting.

\section{$R$ distribution}

The $R$ values were measured using Image J software, following the above-described methodology. The measured $R$ distributions in these two deposits are shown in Fig. 12 . The median $R$ of deposits in each environment was 0.847 (B1), 0.860 (B2), 0.865 (B3), and 0.866 (B4) for the beach deposits and 0.764 (S1), 0.778 (S2), 0.746 (S3), and 0.784 (S4) for the slope deposits. The range between the first and third quartiles of $R$ in the deposits of each environment were 0.821 to 0.869 (B1), 0.831 to 0.860 (B2), 0.835 to 0.889 (B3), and 0.838 to 0.889 (B4) for the beach deposits and 0.703 to 0.804 (S1), 0.759 to 0.792 (S2), 0.726 to 0.776 (S3), and 0.741 to 0.815 (S4) for the slope deposits. Together, these data indicate that the beach deposits were more rounded than the slope deposits.

\section{Comparison between beach and slope deposits using $R$ and grain-size distributions}

Through the examination of both $R$ and grain-size distributions (Fig. 12), distinctive differences between beach and slope deposits are revealed. In order to compare the characteristics of the different deposits, a plot of the mean values and ranges between the first and third quartiles is shown for all samples in Fig. 12. This diagram shows clearly that the areas in which the beach deposits and slope deposits plot are completely separate. The beach deposits had high $R$ values and ranged from coarse-grained sands to granules. In contrast, the slope deposits had low $R$ values and ranged in size from granules to pebbles. These distinct variations imply that there is a significant difference in cumulative energy between the two deposit types. The beach deposits comprise particles that are highly abraded by wave action and beach drift transport, whereas the slope deposits were comparatively unaffected by such physical abrasion. Therefore, the new roundness parameter $R$ can be considered helpful for the study of sedimentary processes and the estimation of particle origins.

\section{Conclusions}

In this study, we propose a new particle roundness parameter, $R$, which can be defined as the circularity corrected by the aspect ratio, and we demonstrate the calculation of this parameter from particle images, using ImageJ software. The results of this study can be summarized as follows: 
1. The basic concept of the new roundness parameter $R$ can be defined as:

$R=$ Circularity $+\left(\right.$ Circularity $_{\text {perfect circle }}-$ Circularity $\left._{\text {aspect ratio }}\right)$

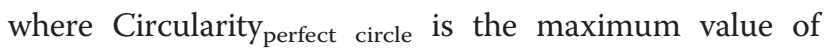

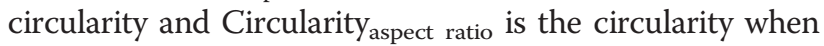
only the aspect ratio varies from that of a perfect circle.

2. The effective diameter of a digital image suitable for $R$ calculations ranges from 100 to 1024 pixels, based on shape analysis of test circle images of various sizes using ImageJ software.

3. The effective aspect ratio of digital images for $R$ calculations ranges from 10:1 to 10:10, based on shape analysis for various test circle and ellipse images in ImageJ software.

4. Given that a digital image is of an appropriate size, circularity $\left(C_{\mathrm{AR}}\right)$ is given by a sixth-degree polynomial with respect to aspect ratio $\left(A R_{I}\right)$ :

$$
\begin{aligned}
C_{\mathrm{AR}}= & 0.826261+0.337479 \cdot \mathrm{AR}_{\mathrm{I}}-0.335455 \cdot \mathrm{AR}_{\mathrm{I}}^{2} \\
& +0.103642 \cdot \mathrm{AR}_{\mathrm{I}}^{3}-0.0155562 \cdot \mathrm{AR}_{\mathrm{I}}^{4} \\
& +0.00114582 \cdot \mathrm{AR}_{\mathrm{I}}^{5}-0.0000330834 \cdot \mathrm{AR}_{\mathrm{I}}^{6}
\end{aligned}
$$

5. The new roundness parameter $R$ is thus defined as:

$$
R=C_{\mathrm{I}}+\left(0.913-C_{\mathrm{AR}}\right)
$$

where $C_{\mathrm{I}}$ is the circularity measured using ImageJ software.

6. Validation of $R$ using the pebble images for visual roundness provided by Krumbein (1941) reveals a strong correlation coefficient $(r=0.937)$ between Krumbein's roundness and $R$.

7. Based on the application of $R$ to modern beach and slope deposits, we can confirm that the new roundness parameter $R$ represents a useful new tool in the analysis of particle shape.

\section{Competing interests}

The authors declare that they have no competing interests.

\section{Authors' contributions}

YT originally produced the ideas for $R$ and designed the study. YT and MI carried out the experimental study of modern sediment particles. All authors read and approved the final manuscript.

\section{Acknowledgements}

We thank the two anonymous reviewers who provided constructive comments and helpful suggestions. This research was partly supported by Grants-in-Aid for Scientific Research from the Japan Society for the Promotion of Science (Y. Takashimizu, no. 24740341). We also acknowledge Dr. A Urabe (Niigata University) who assisted us in sampling.

\section{Author details}

${ }^{1}$ Faculty of Education, Niigata University, Niigata 950-2181, Japan. ${ }^{2}$ Oh-shima Elementary School, Joetsu 942-1103, Japan.

Received: 14 January 2015 Accepted: 27 December 2015 BP?

\section{References}

Abramoff MD, Magalhaes PJ, Ram SJ (2004) Image processing with ImageJ. Biophotonics Int 11:36-42

Arasan S, Akbulut S, Hasiloglu S (2011) The relationship between the fractal dimension and shape properties of particle. J Civil Eng 15:1219-25. doi:10.1007/s12205-011-1310-x

Barrett PJ (1980) The shape of rock particles, a critical review. Sedimentology 27:291-303. doi:10.1111/j.1365-3091.1980.tb01179.x

Blott PJ, Pye K (2008) Particle shape: a review and new methods of characterization and classification. Sedimentology 55:31-63. doi:10.1111/j. 1365-3091.2007.00892.x

Bowman ET, Soga K, Drummond W (2001) Particle shape characterisation using Fourier descriptor analysis. Geotechnique 51:545-54

Clark MW (1981) Quantitative shape analysis: a review. Math Geol 13:303-20. doi:10.1007/BF01031516

Cox EP (1927) A method of assigning numerical and percentage values to the degree of roundness of sand grains. J Paleontol 1:179-83

Diepenbroek M, Bartholomä A, Ibbeken H (1992) How round is round? A new approach to the topic 'roundness' by Fourier grain shape analysis. Sedimentology 39:411-22. doi:10.1111/j.1365-3091.1992.tb02125.x

Drevin RG (2007) Computational methods for the determination of roundness of sedimentary particles. Math Geol 38:871-90. doi:10.1007/s11004-006-9051-y

ImageJ user guide, 2012. ImageJ/Fiji 1.46, p. 187.

Itabashi K, Matsuo M, Naito M, Mori T (2004) Fractal analysis of visual chart of the particle shape and the comparison of shape parameters. Soils Found 44:143-56. doi:10.3208/sandf.44.143 (In Japanese)

Krumbein WC (1941) Measurement and geological significance of shape and roundness of sedimentary particles. J Sediment Petrol 11:64-72. doi:10.1306/ D42690F3-2B26-11D7-8648000102C1865D

Lees $G$ (1963) A new method determining the angularity of particles. Sedimentology 3:2-21. doi:10.1111/j.1365-3091.1964.tb00271.x

Lira C, Pina P (2009) Automated grain shape measurements applied to beach sands. J Coastal Res Spec Issue 56:1527-31

Orford JD, Whalley WB (1983) The use of the fractal dimension to quantify the morphology of irregular-shaped particles. Sedimentology 30:655-68. doi:10.1111/j.1365-3091.1983.tb00700.x

Pettijohn FJ (1957) Sedimentary rocks, 2nd edn. Harper \& Brothers, New York

Powers MC (1953) A new roundness scale for sedimentary particles. J Sediment Petrol 23:117-9. doi:10.1306/D4269567-2B26-11D78648000102 C1865D

Rittenhouse G (1943) A visual method of estimating two-dimensional sphericity. J Sediment Petrol 13:79-81

Roussillon T, Piegay H, Sivignon I, Tougne L, Lavigne F (2009) Automatic computation of pebble roundness using digital imagery and discrete geometry. Comput Geosci 35:1992-2000. doi:10.1016/j.cageo.2009.01.013

Schneider CA, Rasband WS, Eliceiri KW (2012) NIH Image to ImageJ: 25 years of image analysis. Nat Methods 9:671-5. doi:10.1038/nmeth.2089

Schwarcz HP, Shane KC (1969) Measurements of particle shape by Fourier analysis. Sedimentology 13:213-31. doi:10.1111/j.1365-3091.1969. tb00170.x

Shimazu M, Tanaka K, Yoshida T (1970) Geology of the Taro district. Quadrangle series, scale 1:50,000, Akita no. 18, Geol Surv Japan. 54 (In Japanese with English abstract).

Suzuki K, Sakai K, Ohta T (2013) Quantitative evaluation of grain shapes by utilizing Fourier and fractal analysis and implications for discriminating sedimentary environments. J Geol Soc Japan 119:205-16. doi:10.5575/geosoc 2012.0085 (In Japanese with English abstract)

Suzuki K, Fujiwara H, Ohta T (2015) The evaluation of macroscopic and microscopic textures of sand grains using elliptic Fourier and principal component analysis: implications for the discrimination of sedimentary environments. Sedimentology 62:1184-97. doi:10.1111/sed.12183

Vallejo LE, Zhou Y (1995) The relationship between the fractal dimension and Krumbein's roundness number. Soils Found 35:163-7. doi:10.3208/ sandf1972.35.163 
Wadell H (1932) Volume, shape, and roundness of rock particles. J Geol 40:443-51 Winkelmolen AM (1982) Critical remarks on grain parameters, with special emphasis on shape. Sedimentology 29:255-65. doi:10.1111/j.1365-3091.1982.tb01722.x Yoshimura Y, Ogawa S (1993) A simple quantification method of grain shape of granular materials such as sand. Doboku Gakkai RonbunshuJ Japan Soc Civil Eng. No. 463/II-22:95-103 (In Japanese with English abstract). doi: 10.2208/jscej. 1993.463_95

\section{Submit your manuscript to a SpringerOpen ${ }^{\circ}$ journal and benefit from:}

- Convenient online submission

- Rigorous peer review

- Immediate publication on acceptance

- Open access: articles freely available online

- High visibility within the field

- Retaining the copyright to your article

Submit your next manuscript at $>$ springeropen.com 